account for their biological role, although with $\alpha$-tocopherol certain deficiency states involving fat stress could partly involve such properties. Even fat stress, however, is not necessarily related to peroxidation. Schwarz (1954) has shown very clearly that fat stress precipitates liver necrosis in rats, which is entirely prevented by Factor $3 \mathrm{Se}$, which, as we have shown, exerts no antioxidant effects in this system. There is much evidence that points to a so-far undiscovered metabolic role for a derivative of tocopherol, which is closely paralleled, biochemically, by the role of Se.

\title{
REFERENCES
}

Aiyar, A. S. \& Sreenivasan, A. (1961a), Proc. Soc. exp. Biol., N.Y., ro7, 911. Aiyar, A. S. \& Sreenivasan, A. (1961b). Proc. Soc. exp. Biol, N.Y., 107, 914.

Beyer, R. E., Noble, W. M. \& Hirschfield, T. S. (1962). Biochim. biophys. Acta, 57, 376.

Bieri, J. G., Dam, H., Prange, I. \& Sondergaard, E. (I96I). Acta physiol. scand. 52, 36.

Bunyan, J., Diplock, A. T., Edwin, E. E. \& Green, J. (1962). Brit. $\mathscr{F}$. Nutr. (In the Press.)

Caputto, R., McCay, P. B. \& Carpenter, M. P. (1961). Amer. F. clin. Nutr. 9, no. 4, part 2, p. 6r.

Chernick, S. S., Moe, J. G., Rodnan, G. P. \& Schwarz, K. (1955). F. biol. Chem. 217, 829.

Corwin, L. M. \& Schwarz, K. (1959). Y. biol. Chem. 234, 191.

Corwin, L. M. \& Schwarz, K. (1960). F. biol. Chem. 235, 3387.

Dinning, J. S., Sime, J. T. \& Day, P. L. (1955). 7. biol. Chem. 217, 205.

Diplock, A. T., Edwin, E. E., Green, J. \& Bunyan, J. (1961). Biochim. biophys. Acta, 51, 594.

Edwin, E. E., Diplock, A. T., Bunyan, J. \& Green, J. (1961). Biochem. F. 79, 91.

Edwin, E. E., Green, J., Diplock, A. T. \& Bunyan, J. (1960). Nature, Lond., 186, 725.

Gray, D. E. (1959). F. Vitaminology, 5, 19.

Gray, D. E., Chisholm, J. \& Lee Peng, C. H. (I959). F. Vitaminology, 6, 62.

Gray, D. E., Chisholm, J. \& Lee Peng, C. H. (1960). F. Vitaminology, 6, 29 x.

Green, J., Diplock, A. T., Bunyan, J., Edwin, E. E. \& McHale, D. (1961). Nature, Lond., 19o, 318.

Green, J., Edwin, E. E., Bunyan, J. \& Diplock, A. T. (1960). Biochem. F. 75, 456.

Magee, J. (1959). Analyt. Chem. 31, 298.

Mason, K. L. (1944). Vitam. E Horm. 2, 107.

Morgulis, S. \& Spencer, H. C. (1936). I. Nutr. r2, 173.

Morton, R. A. \& Phillips, W. E. J. (I959). Biochem. F. 73, 427.

Phillips, W. E. J. \& Morton, R. A (I959). Biochem. F. 73, 430.

Rodnan, G. P., Chernick, S. S. \& Schwarz, K. (1956). Ұ. biol. Chem. 221, 23 I.

Rosecan, M., Rodnan, G. P., Chernick, S. S. \& Schwarz, K. (I955). F. biol. Chem. 217, 967.

Schwarz, K. (1954). Fed. Proc. 13, 477.

Schwarz, K. (1961a). Amer. F. clin. Nulr. 9, no. 4, part 2, p. 95.

Schwarz, K. (196rb). Amer. F. clin. Nutr. 9, no. 4, part 2, p. 71.

Schwarz, K. \& Foltz, C. M. (1957). F. Amer. chem. Soc. 79, 3292.

Schwarz, K., Mertz, W. \& Simon, E. J. (1959). Biochim. biophys. Acta, 32, 484.

Scott, M. L. (1962). Nutr. Abstr. Rev. 32, 1 .

Slater, E. C. (I96I). Amer. F. clin. Nutr. 9, no. 4, part 2, p. 50.

\section{Muscular dystrophy in man: clinical aspects}

\section{By John N. Walton, Newcastle General Hospital and Royal Victoria Infirmary, Newcastle upon Tyne}

Of the many myopathic disorders which occur in man, muscular dystrophy is most secure in its possession of a separate identity. It can be defined as a genetically determined primary degenerative myopathy (Walton, I96I). I shall discuss briefly here the clinical characteristics of the commoner varieties of human muscular dystrophy, and I shall also mention some of the other varieties of myopathy known 
to occur in man. My colleague (Pennington, 1962) deals with the biochemical aspects of the human disease.

\section{The dystrophic myopathies}

Human progressive muscular dystrophy, being an inherited disorder, is essentially different from the majority of the naturally occurring myopathies that have been described in domestic animals. If we exclude the rare ocular and distal forms of progressive muscular dystrophy, the commonly occurring cases can be divided into three principal groups, which are the Duchenne type, the limb-girdle type and the facioscapulohumeral type (Walton \& Nattrass, 1954). In each of these varieties of the disease, which vary considerably in rate of progress and in mode of inheritance, the muscles predominantly affected are those of the pelvic and shoulder girdles. Weakness of pelvic girdle muscles gives rise to a characteristic clumsy waddling gait, to difficulty in climbing stairs, to a tendency to fall easily, and to an inability to rise from the floor except by 'climbing up the legs'. Weakness of the shoulder girdle muscles gives rise to difficulty in lifting objects and in raising the arms above the shoulders.

Duchenne-type muscular dystrophy. The principal characteristics are (a) expression in the male, rarely in the female; (b) onset usually in the first 3 years of life, but occasionally later; (c) transmission as a sex-linked recessive character, much less commonly as an autosomal recessive; (d) symmetrical involvement first of the pelvic girdle muscles and later of the shoulder girdles; (e) pseudohypertrophy, or enlargement of calf muscles and of deltoids and quadriceps, occurs in $80 \%$ or more of cases; ( $f$ ) abortive or partially affected cases do not occur; (g) there is steady and rapid progression, leading usually to inability to walk within ro years of the onset; (h) progressive deformity with muscular contractures, skeletal distortion and atrophy occurs; (i) death from inanition, respiratory infection or cardiac failure occurs usually in the second decade.

Limb-girdle muscular dystrophy. The characteristics are (a) expression in either sex; (b) onset usually in the second or third decade, but occasionally late in the first decade or in middle life; (c) transmission usually as an autosomal recessive character, but many cases are sporadic; (d) there is primary involvement of either the shoulder girdle muscles or the pelvic girdle, with spread to the other after a variable period of time; (e) muscular pseudohypertrophy occurs but is comparatively uncommon; (f) abortive cases are uncommon; $(\mathrm{g})$ there is variable severity and rate of progression, but disability is usually severe within 20 years of the onset; $(h)$ muscular contractures and skeletal deformity occur only late in the course of the disease; (i) most patients are severely disabled in middle life and die before the normal age.

Facioscapulohumeral muscular dystrophy. The characteristics are (a) expression in either sex; (b) onset at any age from childhood until middle or late adult life; (c) inheritance as an autosomal dominant character; (d) abortive or partially affected cases are common; (e) the disease begins in the face and shoulder girdle muscles, but spreads later to the pelvic girdle; (f) pseudohypertrophy of muscles is very 
uncommon; (g) muscular contractures and skeletal deformity are rare; (h) the progress of the disease is insidious and there are prolonged periods of apparent arrest; occasional cases occur in which the disease is more rapidly progressive, but most patients survive and remain active to a normal age.

Dystrophia myotonica. This is another condition which must be mentioned. In this disorder a progressive dystrophic process affects the peripheral muscles of the limbs, but is associated with the phenomenon of myotonia. This effect is seen particularly well in the hands and gives rise to inability to relax the grip; this phenomenon, which is accompanied by a characteristic electrical after-discharge in the muscles, is accentuated by cold. In some families it involves the whole skeletal musculature and there are no accompanying dystrophic features (myotonia congenita, Thomsen's disease). A similar phenomenon has been observed in goats (Brown \& Harvey, r939). In addition to the features described, patients with dystrophia myotonica develop weakness of the facial muscles, cataracts, frontal baldness and (in the male) testicular atrophy, and weakness of the sternomastoid muscles. This disease is also insidiously progressive.

No form of effective treatment has yet been discovered for any form of human muscular dystrophy, and there is no evidence that nutritional factors play any part in the development of the muscular weakness. It is, however, worth mentioning that human dystrophia myotonica shows certain clinical resemblances to the variety of hereditary muscular dystrophy that has been described in the house mouse of the Bar Harbor strain (Michelson, Russell \& Harman, 1955). Histological examination of specimens of muscle obtained from these mice also reveals changes similar to those observed in human dystrophia myotonica; the resemblance to the changes seen in other varieties of human muscular dystrophy is less striking.

\section{The non-dystrophic myopathies}

Numerous non-dystrophic varieties of myopathy have also been described in man.

Polymyositis. This, one of the most common, is an inflammatory disease of muscles related to the so-called 'connective-tissue' group of diseases, which includes such conditions as rheumatoid arthritis, disseminated lupus erythematosus, dermatomyositis and scleroderma. Polymyositis, if subacute, may resemble muscular dystrophy closely, since it can give rise to similar weakness of proximal limb muscles and there may be very little pain, tenderness or constitutional disturbance (Walton $\&$ Adams, 1958). Certain clinical features help in differential diagnosis, as does electromyography, but muscle biopsy is particularly important. The recognition of cases of polymyositis is most important in view of the fact that most patients with this condition can be effectively treated with drugs of the steroid group. For some reason, not yet fully understood, there seems to be a close relationship between polymyositis and dermatomyositis on the one hand, and malignant disease on the other. A substantial proportion of patients suffering from polymyositis, and more particularly those with dermatomyositis, are eventually found to be harbouring unsuspected malignant neoplasms in the lung or some other organ. 
Metabolic myopathies. There are many metabolic myopathies; among the most common are familial periodic paralysis and its variants. Affected individuals suffer recurrent attacks of widespread muscular paralysis, and are usually found to have changes in the potassium content of the serum during the attacks. In some instances the attacks are associated with a fall in potassium content; in others it is raised. Widespread muscular pain and cramp on exertion may also be a feature of one form of glycogen storage disease of the muscles (McArdle, I95 I), and a different variety of glycogen storage disease may give rise to a generalized hypotonia or limpness of the muscles in infancy (Krivit, Polglase, Gunn \& Tyler, 1953).

Other myopathic disorders. Many other varieties of myopathic disorder in man may result from disorders of the endocrine system. Thus, thyrotoxicosis, or overactivity of the thyroid gland, can give rise to a profound thyrotoxic myopathy with marked weakness of the proximal limb muscles. Weakness and stiffness of muscles with slowness of contraction is also a feature of hypothyroidism (myxoedema). Marked weakness of proximal limb muscles can also be seen in patients suffering from hypopituitarism, and from overactivity (Cushing's syndrome) or underactivity (Addison's disease) of the adrenal cortex. There are also numerous obscure myopathic disorders occurring in early infancy and childhood, many of which give rise to a generalized hypotonia or limpness of the skeletal musculature (Walton, 1957). One recently described rare cause of this syndrome is the so-called 'central core disease' (Shy \& Magee, I956), in which histochemical staining of muscle specimens reveals a curious abnormality of the core of many muscle fibres.

In the space available I have been able to give only a very brief survey of the human myopathies; there are a great many more varieties of muscular disease occurring in man to which I have not referred. One example is the obscure syndrome of myohaemoglobinuria, in which severe attacks of generalized muscular pain occur and there is a rapid output of myoglobin in the urine (Hed, 1947). A similar condition has, of course, been described in animals. I hope, however, I have been able to give some idea of the complex interrelationships of the many human diseases involving the voluntary muscles. Just as a great many new myopathies are being described from time to time in the animal kingdom, so we are continually adding to the list of those known to occur in man. It is my personal opinion that tocopherol metabolism is in no way related to the aetiology of human muscular dystrophy, but Pennington ( 1962 ) now considers this point in detail.

\section{REFERENCES}

Brown, G. L. \& Harvey, A. M. (1939). Brain, 62, 341.

Hed, R. (1 947). Nord. med. 35, 1586.

Krivit, W., Polglase, W. J., Gunn, F. D. \& Tyler, F. H. (1953). Pediatrics, Springfield, 12, I65.

MeArdie, B. (1951). Clin. Sci. ro, 13.

Michelson, A. M., Russell, E. S. \& Harman, P. J. (1955). Proc. nat. Acad. Sci., Wash., 4I, 1079.

Pennington, R. J. (1962). Proc. Nutr. Soc, 16, 206.

Shy, G. M. \& Magee, K. R. (1956). Brain, 79, 6ro.

Walton, J. N. (1957). F. Neurol. Psychiat. 20, 144.

Walton, J. N. (r961). Res. Publ. Ass. nerv. ment. Dis. 38, 378.

Walton, J. N. \& Adams, R. D. (1958). Polymyositis. Edinburgh: E. \& S. Livingstone Ltd.

Walton, J. N. \& Nattrass, F. J. (I954). Brain, 77, r69. 